\title{
Article
}

\section{Photoprotective Bioactivity Present in a Unique Marine Bacteria Collection from Portuguese Deep Sea Hydrothermal Vents}

\author{
Ana Martins ${ }^{1}$, Tania Tenreiro ${ }^{2}$, Gonçalo Andrade ${ }^{1}$, Mário Gadanho ${ }^{2}$, Sandra Chaves ${ }^{2}$, \\ Marta Abrantes ${ }^{1}$, Patrícia Calado ${ }^{1}$, Rogério Tenreiro ${ }^{2}$ and Helena Vieira ${ }^{1, *}$ \\ 1 BIOALVO, SA TEC LABS - Innovation Center, Campus of FCUL, Campo Grande, 1749-016 \\ Lisbon, Portugal; E-Mails: ana.martins@bioalvo.com (A.M.); goncalo.andrade@bioalvo.com (G.A.); \\ marta.abrantes@bioalvo.com (M.A.); patricia.calado@bioalvo.com (P.C.) \\ 2 University of Lisbon, Faculty of Sciences, Centre for Biodiversity, Functional and Integrative \\ Genomics (BioFIG), Campus of FCUL, Campo Grande, 1749-016 Lisbon, Portugal; \\ E-Mails: taniatenreiro@biosurfit.com (T.T.); mariogadanho@ biopremier.com (M.G.); \\ sichaves@fc.ul.pt (S.C.); rptenreiro@fc.ul.pt (R.T.) \\ * Author to whom correspondence should be addressed; E-Mail: helena.vieira@ bioalvo.com; \\ Tel.: +35-121-750-0101; Fax: +35-121-750-0220.
}

Received: 13 March 2013; in revised form: 16 April 2013 / Accepted: 23 April 2013 /

Published: 10 May 2013

\begin{abstract}
Interesting biological activities have been found for numerous marine compounds. In fact, screening of phylogenetically diverse marine microorganisms from extreme environments revealed to be a rational approach for the discovery of novel molecules with relevant bioactivities for industries such as pharmaceutical and cosmeceutical. Nevertheless, marine sources deliverables are still far from the expectations and new extreme sources of microbes should be explored. In this work, a marine prokaryotic collection from four Mid-Atlantic Ridge (MAR) deep sea hydrothermal vents near the Azores Islands, Portugal, was created, characterized and tested for its photoprotective capacity. Within 246 isolates, a polyphasic approach, using chemotaxonomic and molecular typing methods, identified 23-related clusters of phenetically similar isolates with high indexes of diversity. Interestingly, 16S rRNA gene sequencing suggested the presence of $43 \%$ new prokaryotic species. A sub-set of 139 isolates of the prokaryotic collection was selected for biotechnological exploitation with 484 bacterial extracts prepared in a sustainable upscalling manner. $22 \%$ of the extracts showed an industrially relevant photoprotective activity, with two extracts, belonging to new strains of the species
\end{abstract}


Shewanella algae and Vibrio fluvialis, uniquely showing UV-A, UV-B and UV-C protective capacity. This clearly demonstrates the high potential of the bacteria MAR vents collection in natural product synthesis with market applications.

Keywords: deep sea; marine bacteria; natural products; MAR hydrothermal vents; photoprotection

\section{Introduction}

Screening of phylogenetically diverse and unique organisms from rare or extreme ecosystems has been used to discover relevant bioactivities. In the 1960s, efforts to sample the deep ocean floor resulted in unexpected findings of high faunal diversity, turning the marine environment into a top spot for the search of biological active compounds. Up to now, bioactivities such as anti-tumor, anti-microtubule, anti-proliferative, photoprotective, as well as antibiotic and anti-fouling have been identified in the marine environment [1]. However, it was the disclosure of the role of bacteria in the production of bryostatins that opened the road for the biotechnological synthesis of anti-tumor compounds from marine origin [2,3] and triggered the interest in marine microbial resources from many biotechnological angles [4].

Nevertheless, to maximize the chemical diversity available from microorganisms, and their translation into suitable commercial products, new extreme sources of microbes are needed. Deep sea hydrothermal vents, with physical extremes of temperature $\left(4\right.$ to $\left.400{ }^{\circ} \mathrm{C}\right)$ and pressure, a complete absence of light and abrupt chemical, $\mathrm{pH}$ and temperature gradients, are considered one of the most extreme and dynamic environments on Earth. The most studied hydrothermal systems are located in the eastern Pacific and in the north-central Atlantic [5]. The Mid-Atlantic Ridge (MAR), that extends from the Arctic Ocean to the African Continent, is mainly constituted by submerged mountains [6] and harbours several hydrothermal fields such as Menez Gwen, Menez Hom, Rainbow, Lucky Strike and Mount Saldanha [7].

Despite the high scientific and commercial interest in the microbial ecology of these ecosystems, relatively little is known about the diversity of functional taxonomic groups of free-living microbes that occupy these niches as well as their biotechnological potential. Culture-dependent and culture-independent methods have been employed with the Proteobacteria phylum comprising approximately one-third of all known bacteria present at the deep sea hydrothermal vents [7-9].

In this work, a marine prokaryotic collection from four MAR hydrothermal vents, Menez Gwen, Rainbow, Lucky Strike and Mount Saldanha (Figure 1) was created. Upon isolation of the marine prokaryotes, a polyphasic approach [10,11] was applied which allowed the definition of clusters of isolates and the identification of some prokaryotic species. In order to exploit the bioactivity potential of this unique collection, an industrially relevant sub-set of crude bacterial extracts was prepared and a yeast-based platform that relies on yeast susceptibility to UV radiation [12] was developed allowing the identification of deep sea crude extracts with photoprotection activity. It is known that although some UV radiation can have beneficial effects, as it stimulates vitamin D production [13], too much exposure to UV radiation is generally harmful and needs blockage. Examples of injuries caused by UV 
radiation include collagen fibre damage that accelerates skin aging and, ultimately, skin cancer [14]. Some compounds were already described acting as sunscreens, with the best known being the melanins present in humans and other animals and even in some bacteria, black yeasts and pigmented filamentous fungi [15-17]. In addition to melanins, other compounds such as scytonemins from cyanobacteria, mycosporines from fungi and mycosporine-like amino acids from cyanobacteria, algae and animals have been used to counteract photodamage [18]. Nevertheless, the discovery of new-generation natural sunscreens with improved characteristics such as a broad and intense absorption bands together with a high degree of photostability is of high interest and may be found in deep sea crude extracts.

Figure 1. Portuguese mission SEAHMA-1 in MAR (Mid-Atlantic Ridge). (a) Localization and images of five hydrothermal vents visited during the missions: Rainbow, Mount Saldanha, Lucky Strike and Menez Gwen; (b) Images of the ship L'Atlante and of the ROV (Remote operating vehicle) Victor 6000 used in the expedition.
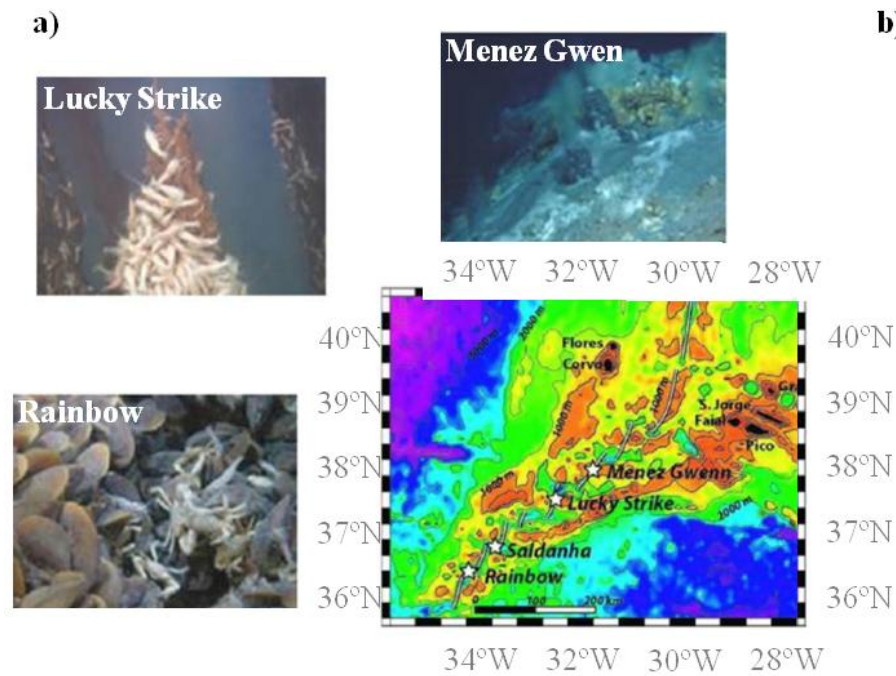

b)
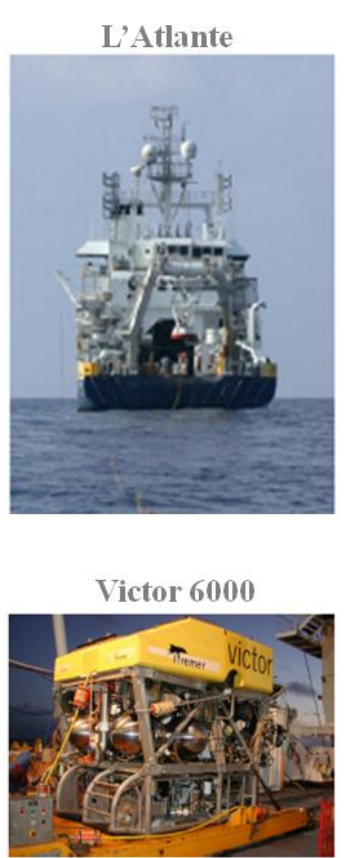

\section{Results and Discussion}

\subsection{New Marine Prokaryotes Isolates from MAR Vents}

From the 36 samples collected from the MAR hydrothermal vents visited (Supplemental Table S1), two of them, MH1 and RB1 were used only for the isolation of yeasts that were described elsewhere [19], whereas all other 34 samples were used in this work for prokaryotes isolation. From the 34 samples initially inoculated, 25 collected from four MAR hydrothermal vents, allowed the isolation, and further growth in standardized culturing conditions, of 289 marine prokaryotes. Based on oxygen demand and growth temperature, three phenotypic operational groups were defined. Group I contains 140 psychrotolerant aerobes, group II contains 125 psychrotolerant anaerobes and group III 
contains 24 thermophilic anaerobes (Table 1). In relation to the standardized culturing conditions, microorganisms belonging to group I could be grown on Nutrient Broth supplemented with $3 \%$ sea salts at $22{ }^{\circ} \mathrm{C}$ for $72 \mathrm{~h}$, group II microorganisms could be grown on the same media as group I but supplemented with $0.05 \%$ cysteine and incubated at $22{ }^{\circ} \mathrm{C}$ for $96 \mathrm{~h}$ whereas group III microorganisms could be grown on the same medium as group II although different incubation temperatures were needed for optimal growth.

Table 1. Distribution of the MAR vents isolates in each phenotypic operational group according to the type of sample (a) and hydrothermal vent (b) from which they were collected.

\begin{tabular}{llcccccc}
\hline & & \multicolumn{5}{c}{ Type of sample } \\
\cline { 3 - 7 } & & Water & Animals & Sediments & Chimneys & Total \\
\cline { 3 - 8 } Phenptypic operational group & II & 18 & 87 & 24 & 11 & $\mathbf{1 4 0}$ \\
& III & 11 & 56 & 44 & 14 & $\mathbf{1 2 5}$ & $\mathbf{2 4}$ \\
& Total & $\mathbf{2 9}$ & $\mathbf{1 4 6}$ & $\mathbf{6 8}$ & $\mathbf{4 6}$ & $\mathbf{2 8 9}$ \\
\hline
\end{tabular}

(a)

\begin{tabular}{llcccccc}
\hline & & \multicolumn{5}{c}{ Hydrothermal vent } \\
\cline { 3 - 7 } & & & $\begin{array}{c}\text { Menez } \\
\text { Gwen }\end{array}$ & $\begin{array}{c}\text { Lucky } \\
\text { Strike }\end{array}$ & $\begin{array}{c}\text { Mount } \\
\text { Saldanha }\end{array}$ & Rainbow & Total \\
\cline { 3 - 7 } Phenptypic operational group & I & 57 & 32 & 3 & 48 & $\mathbf{1 4 0}$ \\
& II & 82 & 15 & 0 & 28 & $\mathbf{1 2 5}$ \\
& III & 1 & 11 & 0 & 12 & $\mathbf{2 4}$ \\
& Total & $\mathbf{1 4 0}$ & $\mathbf{5 8}$ & $\mathbf{3}$ & $\mathbf{8 8}$ & $\mathbf{2 8 9}$ \\
\hline
\end{tabular}

(b)

\subsection{MAR Vents Prokaryotic Biodiversity}

246 isolates were further studied by allying a polyphasic characterization approach to a strain clustering strategy. The chemotaxonomic and molecular typing methods whole-cell protein profiling by SDS-PAGE and PCR fingerprinting were applied single and in combination. In relation to the PCR fingerprinting technique, minisatellite primer csM13 and random primers $\mathrm{pH}$ and 1281, targeting different genomic regions, were used. Using this last technique, 245 profiles were obtained with csM13-PCR fingerprinting, 244 profiles were obtained with $\mathrm{pH}-\mathrm{PCR}$ fingerprinting and 233 profiles were obtained with primer 1281 . The reproducibility of the fingerprinting profiles, expressed by the percentage of similarity obtained with $10 \%$ randomly chosen replicas, was $75 \% \pm 12.4 \%$ for the M13 primer, $83 \% \pm 10.5 \%$ for the $\mathrm{pH}$ primer and $81 \% \pm 11.3 \%$ for the 1281 primer. From a composite dendrogram of PCR fingerprints, Shannon (J') and Simpson (D') biodiversity indexes of 0.836 , 0.818 and 0.832 for $\mathrm{J}$ ' and $0.785,0.805$ and 0.643 for D' were obtained for the operational groups I, II and III, respectively. Regarding the whole-cell protein profiling, the 246 isolates were firstly grown under standardized culturing conditions defined for each operational group, allowing the detection of 212 whole-cell protein profiles. The average reproducibility of the whole cell protein profiles, estimated as above, was of $81 \% \pm 11.5 \%$. Biodiversity indexes of $0.800,0.561$ and 0.596 for $\mathrm{J}$ ' and $0.643,0.561$ and 0.450 for D' were obtained for the operational groups I, II and III, respectively. The 
combination of the two techniques allowed the construction of consensus polyphasic dendrograms for each phenotypic operational group with the subsequent identification of 23 related clusters of phenetically similar isolates (Figure 2). This multiple integrated approach has led to a more robust dataset showing that incorporation of data from multiple methods leads to consensus dendrograms with a better fit than the one obtained when each method is used alone. 10 clusters were identified in group I, 8 clusters in group II and 5 clusters in group III. The distribution of the isolates in each cluster, based on sampling site and type of sample, is presented in Table 2. Global biodiversity indexes of 0.826 , 0.816 and 0.773 for J' and $0.823,0.702$ and 0.652 for D' were obtained for the operational groups I, II and III, respectively. Based on these indexes, it is also observed that the phenetic diversity decreases from group I to group III, which is in accordance with the number of clusters identified in each group. In relation to group III, it is likely that the low indexes of diversity obtained are due to the fact that this group contains the most difficult microorganisms to cultivate, which might act as a biodiversity bias. A sub-set of isolates from the recognized clusters were identified by $16 \mathrm{~S}$ rRNA gene sequencing and phylogenetically allocated. Although the majority of the sequences analyzed belong to already known prokaryotic species, for $43 \%$ of the sequences only genus level homology was observed (data not shown). In these cases, the similarities values obtained with other known species were lower than $98 \%$, indicative of a high probability that almost half of this collection is constituted by new prokaryotic species [20] making it very appealing for the search of new industrially relevant bioactivities.

Figure 2. Consensus polyphasic dendrograms from the in silico analysis of the PCR fingerprinting profiles (primers csM13, $\mathrm{pH}$ and 1281) and whole-cell protein profiles obtained for Group III (a); Group II (b) and Group I (c). Cophenetic correlation coefficient, $\rho=0.91$.

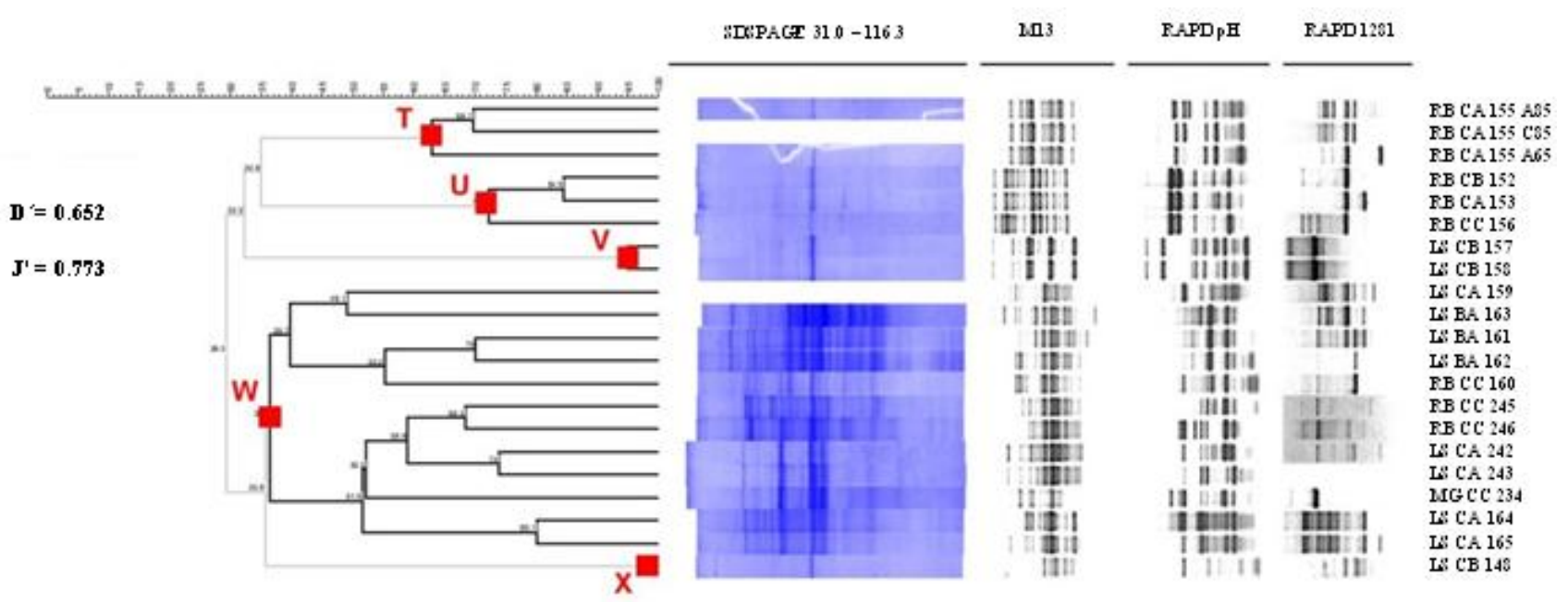

(a) 
Figure 2. Cont.

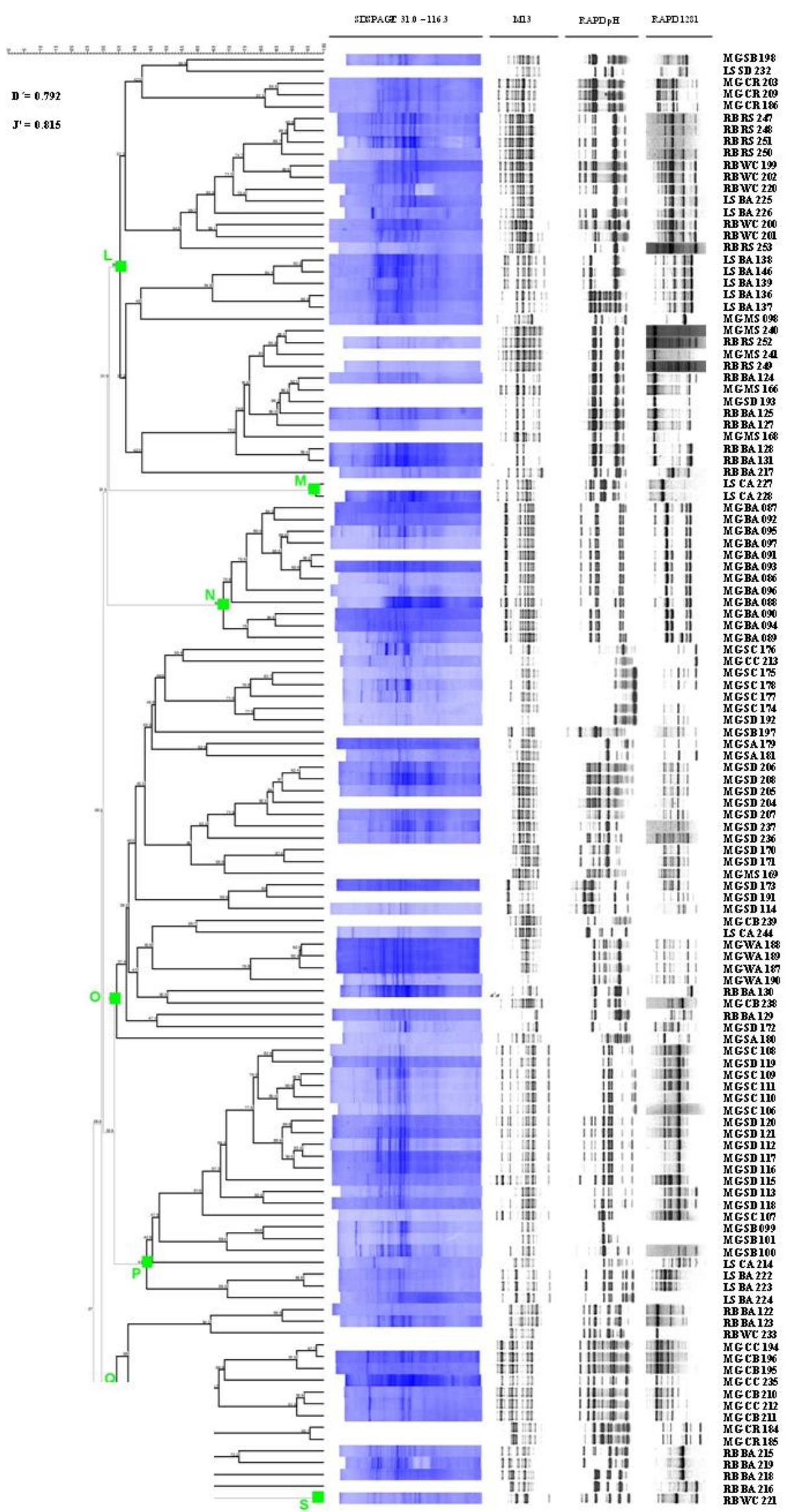

(b) 
Figure 2. Cont.

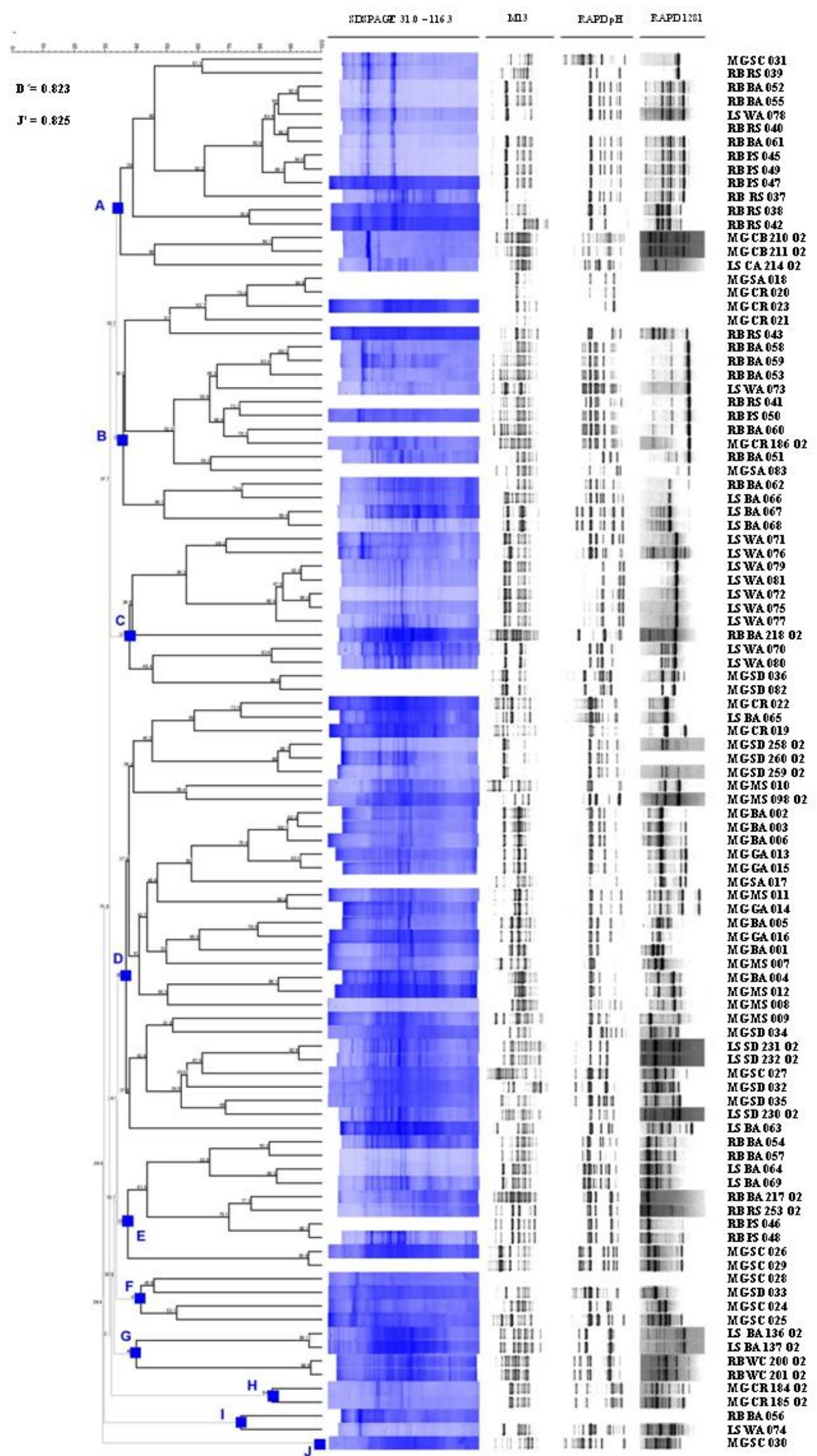

(c) 


\subsection{A MAR Vents Bacteria Collection Suitable for Industry}

In order to economically explore the biotechnological potential of the identified isolates, a sub-set of the collection was selected for commercial exploitation and technology transfer from academic research institutes (MAR vents biotech collection). The selected bacteria isolates were the ones whose industrial scale production would be economically viable, such as low salt concentrations supported (less than 4\%), regular growth temperature $\left(20-40{ }^{\circ} \mathrm{C}\right)$ and effective growth in the presence of oxygen. Optimized general conditions for laboratory growth, where highest yields are obtained in the shortest incubation time, were achieved for 139 psychrotolerant aerobic or facultative anaerobic isolates representative of all MAR vents (Table 3). In addition, stress growth conditions were also tested to further increase the diversity of secondary metabolites being produced. Furthermore, optimization of downstream extraction methods was also performed, allowing to obtain high amounts of dry weight aqueous extract per liter of culture in a sustainable manner. Currently, the MAR vents bacteria extract library comprises 484 extracts, including 212 organic extracts and 272 aqueous extracts.

Table 2. Distribution of the isolates of each one of the 23 identified clusters according to the type of sample (a) and hydrothermal vent (b) from which they were collected.

\begin{tabular}{|c|c|c|c|c|c|}
\hline \multirow[b]{2}{*}{ Group } & \multirow[b]{2}{*}{ Cluster } & \multicolumn{4}{|c|}{ Type of sample } \\
\hline & & Water & Animals & Sediments & Chimneys \\
\hline \multirow{10}{*}{ I } & A & 1 & 11 & 1 & 3 \\
\hline & B & 1 & 16 & 2 & \\
\hline & $\mathrm{C}$ & 9 & 1 & 2 & \\
\hline & D & & 21 & 11 & \\
\hline & $\mathbf{E}$ & & 8 & 2 & \\
\hline & $\mathbf{F}$ & & & 4 & \\
\hline & G & 2 & 2 & & \\
\hline & $\mathbf{H}$ & & 2 & & \\
\hline & I & 1 & 1 & & \\
\hline & $\mathbf{J}$ & & & 1 & \\
\hline \multirow{7}{*}{ II } & $\mathbf{L}$ & 5 & 28 & 3 & \\
\hline & $\mathbf{M}$ & & & & 2 \\
\hline & $\mathbf{N}$ & & 12 & & \\
\hline & $\mathbf{O}$ & 4 & 3 & 23 & 4 \\
\hline & $\mathbf{P}$ & & 3 & 18 & 1 \\
\hline & $\mathbf{Q}$ & & 5 & & 7 \\
\hline & $\mathbf{R}$ & & 4 & & \\
\hline \multirow{6}{*}{ III } & $\mathbf{S}$ & & 1 & & \\
\hline & $\mathbf{T}$ & & & & 3 \\
\hline & $\mathbf{U}$ & & & & 3 \\
\hline & $\mathbf{V}$ & & & & 2 \\
\hline & $\mathbf{W}$ & & 3 & & 9 \\
\hline & $\mathbf{X}$ & & & & 1 \\
\hline
\end{tabular}

(a) 
Table 2. Cont.

\begin{tabular}{|c|c|c|c|c|c|}
\hline \multirow[b]{2}{*}{ Group } & \multirow[b]{2}{*}{ Cluster } & \multicolumn{4}{|c|}{ Hydrothermal vent } \\
\hline & & Menez Gwen & Lucky Strike & Mount Saldanha & Rainbow \\
\hline \multirow{10}{*}{$\mathbf{I}$} & $\mathbf{A}$ & 3 & 2 & 11 & \multirow{10}{*}{3} \\
\hline & B & 6 & 4 & 9 & \\
\hline & $\mathbf{C}$ & 2 & 9 & 1 & \\
\hline & D & 24 & 5 & & \\
\hline & $\mathbf{E}$ & 2 & 2 & 6 & \\
\hline & $\mathbf{F}$ & 4 & & & \\
\hline & G & & 2 & 2 & \\
\hline & $\mathbf{H}$ & 2 & & & \\
\hline & I & & 1 & 1 & \\
\hline & $\mathbf{J}$ & 1 & & & \\
\hline \multirow{7}{*}{ II } & $\mathbf{L}$ & 10 & 8 & 18 & \\
\hline & $\mathbf{M}$ & & 2 & & \\
\hline & $\mathbf{N}$ & 12 & & & \\
\hline & $\mathbf{O}$ & 31 & 1 & 2 & \\
\hline & $\mathbf{P}$ & 18 & 4 & & \\
\hline & $\mathbf{Q}$ & 9 & & 3 & \\
\hline & $\mathbf{R}$ & & & 4 & \\
\hline \multirow{6}{*}{ III } & $\mathbf{S}$ & & & 1 & \\
\hline & $\mathbf{T}$ & & & 3 & \\
\hline & $\mathbf{U}$ & & & 3 & \\
\hline & $\mathbf{V}$ & & & 2 & \\
\hline & $\mathbf{W}$ & 1 & 8 & 3 & \\
\hline & $\mathbf{X}$ & & 1 & & \\
\hline
\end{tabular}

(b)

Table 3. MAR vents biotech collection. MAR vents collection is composed of marine bacteria isolated from different types of samples and from the different hydrothermal fields.

\begin{tabular}{|c|c|c|c|c|}
\hline Marine Strain & Vent & Type of sample & Depth (m) & $\mathbf{T}\left({ }^{\circ} \mathbf{C}\right)$ \\
\hline MG BA 001 to 006 & \multirow{6}{*}{ Menez Gwen } & Bathymordiolus azoricus & 825 & 8.4 \\
\hline MG MS 007 to 012 & & Microcaris sp. & 825 & 8.2 \\
\hline MG GA 013 to 016 & & Gastropode & 825 & 8.4 \\
\hline MG SA 017 and 018 & & Sediment A & 825 & 8.7 \\
\hline MG CR 019 to 023 & & Crab & 825 & 8.2 \\
\hline MG SC 024 to 036 & & Sediment C & 869 & 8.3 \\
\hline RB RS 037 to 043 & \multirow{3}{*}{ Rainbow } & Rimicaris sp. & 2296 & 3.7 \\
\hline RB PS 045 to 050 & & Pachicara sp. & 2297 & 3.7 \\
\hline RB BA 051 to 062 & & Bathymordiolus azoricus & 2290 & 3.8 \\
\hline LS BA 063 to 069 & \multirow{2}{*}{ Lucky Strike } & Bathymordiolus azoricus & 1693 & 4.4 \\
\hline LS WA 070 to 081 & & Water & 1728 & 4.3 \\
\hline MG SD 082 & \multirow{3}{*}{ Menez Gwen } & Sediment D & 808 & 9.1 \\
\hline MG SA 083 & & Sediment A & 825 & 8.7 \\
\hline MG MS $098 \mathrm{O}_{2}$ & & Microcaris sp. & 825 & 8.2 \\
\hline
\end{tabular}


Table 3. Cont.

\begin{tabular}{|c|c|c|c|c|}
\hline $\begin{array}{l}\text { RB BA } 124 \mathrm{O}_{2}, 125 \mathrm{O}_{2}, 127 \mathrm{O}_{2}, \\
128 \mathrm{O}_{2} \text { and } 131 \mathrm{O}_{2}\end{array}$ & Rainbow & Bathymordiolus azoricus & 2290 & 3.8 \\
\hline $\begin{array}{l}\text { LS BA } 136 \mathrm{O}_{2}, 137 \mathrm{O}_{2}, 138 \mathrm{O}_{2} \\
139 \mathrm{O}_{2} \text { and } 146 \mathrm{O}_{2}\end{array}$ & Lucky Strike & Bathymordiolus azoricus & 1693 & 4.4 \\
\hline MG MS $168 \mathrm{O}_{2}$ and $184 \mathrm{O}_{2}$ & \multirow{4}{*}{ Menez Gwen } & Microcaris sp. & 825 & 8.2 \\
\hline MG CR $184 \mathrm{O}_{2}, 185 \mathrm{O}_{2}$ and $186 \mathrm{O}_{2}$ & & Crab & 825 & 8.2 \\
\hline MG CC $194 \mathrm{O}_{2}$ & & Chimney C & 808 & 266.2 \\
\hline MG CB $195 \mathrm{O}_{2}$ and $196 \mathrm{O}_{2}$ & & Chimney B & 865 & 266.2 \\
\hline $\begin{array}{l}\text { RB WC } 199 \mathrm{O}_{2}, 200 \mathrm{O}_{2}, 201 \mathrm{O}_{2} \\
\text { and } 202 \mathrm{O}_{2}\end{array}$ & Rainbow & Water & 2301 & 3.7 \\
\hline MG CR $203 \mathrm{O}_{2}$ and $209 \mathrm{O}_{2}$ & \multirow{3}{*}{ Menez Gwen } & Crab & 825 & 8.2 \\
\hline $\mathrm{MG} \mathrm{CB} 210 \mathrm{O}_{2}$ and $211 \mathrm{O}_{2}$ & & Chimney B & 865 & 266.2 \\
\hline MG CC $212 \mathrm{O}_{2}$ and $213 \mathrm{O}_{2}$ & & Chimney C & 808 & 266.2 \\
\hline LS CA $214 \mathrm{O}_{2}$ & Lucky Strike & Chimney A & 1728 & 231.3 \\
\hline $\begin{array}{l}\text { RB BA } 215 \mathrm{O}_{2}, 216 \mathrm{O}_{2}, 217 \mathrm{O}_{2}, \\
218 \mathrm{O}_{2} \text { and } 219 \mathrm{O}_{2}\end{array}$ & \multirow[t]{2}{*}{ Rainbow } & Bathymordiolus azoricus & 2290 & 3.8 \\
\hline RB WC $220 \mathrm{O}_{2}$ and $221 \mathrm{O}_{2}$ & & Water & 2301 & 3.7 \\
\hline LS BA $225 \mathrm{O}_{2}$ and $226 \mathrm{O}_{2}$ & \multirow{3}{*}{ Lucky Strike } & Bathymordiolus azoricus & 1693 & 4.4 \\
\hline LS CA $227 \mathrm{O}_{2}$ and $228 \mathrm{O}_{2}$ & & Chimney A & 1728 & 231.3 \\
\hline LS SD $230 \mathrm{O}_{2}, 231 \mathrm{O}_{2}$ and $232 \mathrm{O}_{2}$ & & Sediment D & 1691 & 4.3 \\
\hline MG CC $235 \mathrm{O}_{2}$ & \multirow{2}{*}{ Menez Gwen } & Chimney C & 808 & 266.2 \\
\hline MG MS $240 \mathrm{O}_{2}$ and $241 \mathrm{O}_{2}$ & & Microcaris sp. & 825 & 8.2 \\
\hline $\begin{array}{l}\text { RB RS } 247 \mathrm{O}_{2}, 248 \mathrm{O}_{2}, 249 \mathrm{O}_{2}, \\
250 \mathrm{O}_{2}, 251 \mathrm{O}_{2}, 252 \mathrm{O}_{2} \text { and } 253 \mathrm{O}_{2}\end{array}$ & Rainbow & Rimicaris sp. & 2296 & 3.7 \\
\hline MG SD $258 \mathrm{O}_{2}, 259 \mathrm{O}_{2}$ and $260 \mathrm{O}_{2}$ & Mount Saldanha & Sediment D & 2200 & 3.8 \\
\hline
\end{tabular}

\subsection{MAR Vents Bacteria Extracts Possess Photoprotection Capacity}

The development of anti-UV products showing high degree of photostability, capacity to be retained by the skin and the lack of allergenic potential is of high interest for several industries [17]. Searching in nature for products with such properties is an attractive strategy as a high number of microorganisms have already developed photoprotection and there are not yet available natural anti-UV protectors on the market. To explore MAR vents bacteria extracts photoprotection capacity, a yeast-based assay was developed subjecting the cells to either UV-A or UV-C minimum lethal dose of radiation in the presence or in the absence of the extracts. An extract with UV-protective capacity would allow the yeast cells to proliferate and form colonies, whereas a non protective extract would not allow cell growth. Firstly, a minimum lethal dose of $1.2 \mathrm{~J} / \mathrm{cm}^{2}$ was identified for the UV-C lamp whereas a minimum lethal dose of $42 \mathrm{~J} / \mathrm{cm}^{2}$ was the one identified for the UV-A lamp, being these the doses used in the screening. As a result, 2 out of the 24 tested aqueous extracts allowed yeast growth following a lethal dose of UV-A. In the case of UV-C, 16 out of the 57 tested aqueous extracts showed a radiation protection. Interestingly, 2 aqueous extracts, from $\mathrm{MGMS}_{2} 41 \mathrm{O}_{2}$ and $\mathrm{RBRS} 251 \mathrm{O}_{2}$ isolates, showed both anti-UV-A, and anti-UV-C protective capacity (Figure 3a). UV-B photoprotection of these two extracts was also observed, under a minimum lethal dose of $0.084 \mathrm{~J} / \mathrm{cm}^{2}$ (Figure 3a). In order to confirm 
that these extracts can be considered UV absorbers, absorption spectra were obtained with both extracts showing broad absorption spectra from 250 to at least $375 \mathrm{~nm}$ with a peak around $280 \mathrm{~nm}$ (Figure $3 b$ ).

Figure 3. Anti-UV platform and extracts screening. (a) Results for yeast cell growth obtained after 3 days incubation at $30{ }^{\circ} \mathrm{C}$ of 3 plate sets: following non-irradiation and following either UV-A $(365 \mathrm{~nm})$, UV-B $(312 \mathrm{~nm})$ or UV-C $(255 \mathrm{~nm})$ lethal dose irradiation without or with the addition of a 2 to $4 \mu \mathrm{L}$ drop of natural extracts from MGMS241O2 and RBRS251O2 isolates and also of a DMSO control; (b) UV-VIS spectra of natural extracts from MGMS241O2 and RBRS251O2 isolates and also of a DMSO control.
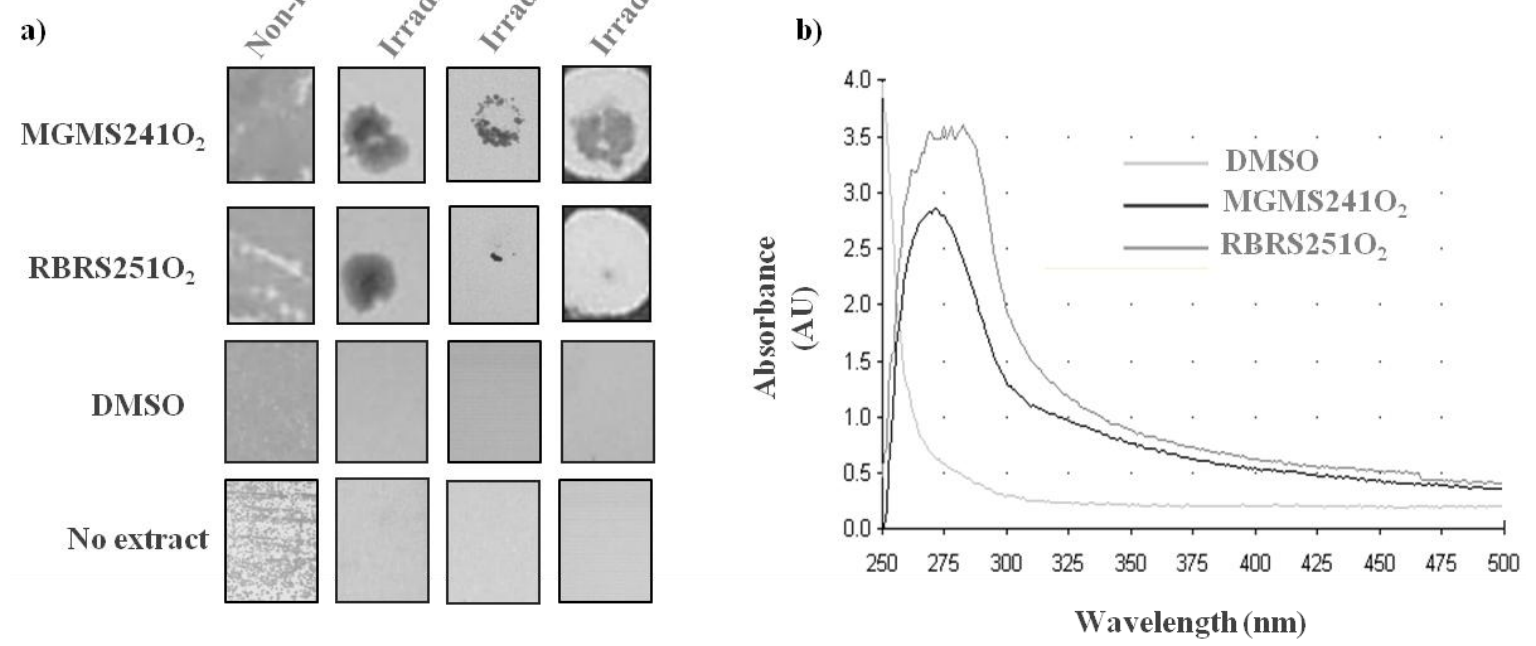

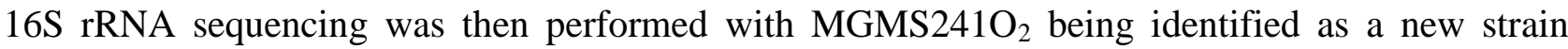
belonging to the species Shewanella algae and $\mathrm{RBRS} 251 \mathrm{O}_{2}$ as a new strain belonging to the species Vibrio fluvialis (Figure 4). Interestingly, as a nonfermenting facultative anaerobe, Shewanella algae has already been described as producing melanin to be used as an electron acceptor when oxygen concentration is low [21] but its role in photoprotection is much less studied. In the case of Vibrio fluvialis, to our knowledge, no photoprotection studied has been reported so far. In fact, melanin has been described as a virulence factor in pathogenic free-living strains of Vibrio cholera [22] and there are already some strains described as UV resistant [23] but no photoprotective activity neither photoprotective compounds have been described for Vibrio fluvialis. Hence, this is the first time that a photoprotection activity is identified for Vibrio fluvialis and that may be specific for this new isolated strain. 
Figure 4. Phylogenetic tree (Bayesian MCMC method) obtained with 16S rRNA sequences (1250 nucleotide positions), corresponding to the sequences determined in this work, the most closely related ones retrieved from BLAST search and representatives of Vibrio and Shewanella genera. Escherichia coli was included to root the tree. Numbers associated to each node refer to probability values. Access numbers of GenBank sequences are indicated and names in bold face correspond to sequences determined in this work. T: type strain.

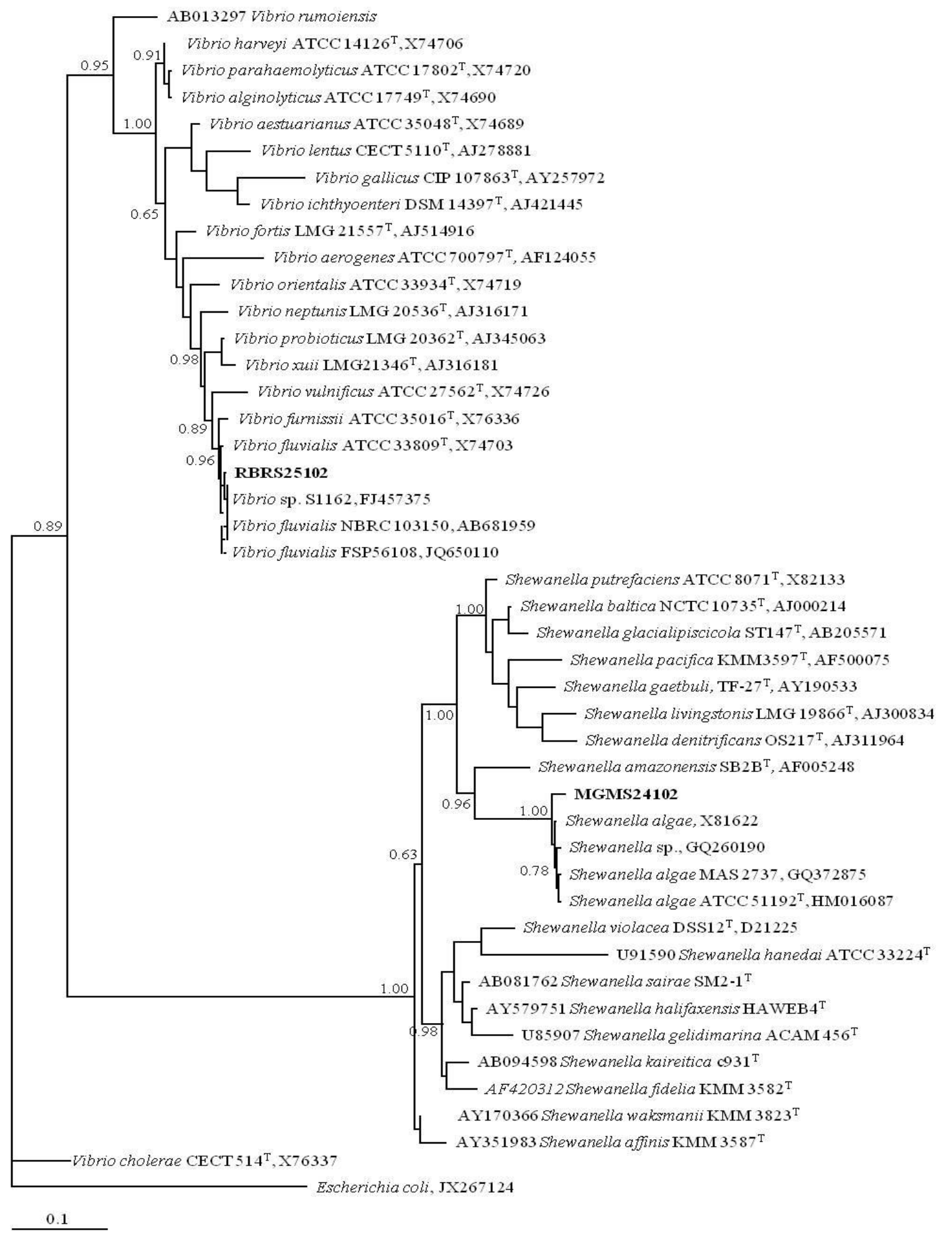




\section{Experimental Section}

\subsection{Marine Bacteria Isolation and Culturing}

During the Portuguese research mission SEAHMA-I, five MAR sites along the Azores archipelago (Menez Gwen, Lucky Strike, Mount Saldanha, Rainbow and Menez Hom) were monitored. Deep-sea sampling was performed using the submersible VICTOR 6000 and 36 samples were collected (Supplemental Table S1). Sample processing started on board using the experimental procedures depicted in Supplemental Figure S1 and several sea salts based culture media suitable for the isolation of marine aerobic and anaerobic bacteria (see Supplemental Table S2 for media composition) were used. After isolation, isolates were grown in a commercial culturing media $(0.5 \%$ peptone (w/v), $0.3 \%$ meat extract (w/v)) supplemented with $3 \%$ sea salts.

\subsection{PCR Fingerprinting and Whole-Cell Protein Profiling and Phylogenetic Analysis}

DNA was extracted from the isolates obtained in culture as described in [24] and stored at $4{ }^{\circ} \mathrm{C}$. PCR fingerprinting with the minisatellite primer $c s \mathrm{M} 13$ (GAGGGTGGCGGTTCT) and random primers $\mathrm{pH}$ (AAGGAGGTGATCCAGCCGCA) and 1281 (AACGCGCAAC) were applied as described elsewhere [25]. Whole-cell protein (WCP) extracts were prepared according to [11] using cultures grown from 72 to $96 \mathrm{~h}$ in Nutrient Broth supplemented with 3\% sea salts. WCP profiles were obtained by SDS-PAGE using a $10 \%$ acrylamide gel in a Tris-HCl buffer, $80 \mu \mathrm{g}$ of total protein per lane and Coomassie blue staining for protein visualization. PCR fingerprints and WCP profiles were analyzed by hierarchical clustering with BioNumerics software (Applied Maths), using Pearson's correlation coefficient and UPGMA agglomeration. Shannon evenness (H') and Simpson diversity (D') indexes [26,27] were used to assess biodiversity levels. Reproducibility of PCR fingerprinting and WCP profiling was estimated as the average percentage of similarity amongst clustered duplicates, using $10 \%$ of randomly chosen duplicates. Molecular identification was performed for a sub-set of isolates belonging to selected clusters. $16 \mathrm{~S}$ rRNA gene was amplified with universal primers $21 \mathrm{~F}$ and $1392 \mathrm{R}$ and DNA sequencing was performed using the same primers on the automated sequencer CEQ 2000-XL (Beckman Coulter, EUA). For phylogenetic analysis, sequence alignments were made with Clustal X [28] and visually corrected. The Bayesian Markov chain Monte Carlo (MCMC) method of phylogenetic inference [29] was applied to estimate phylogenetic relationships using MrBayes software [30].

\subsection{Bacteria Collection Selection and Extracts Preparation and Analysis}

A sub-set of the isolates was selected for commercial purposes. Psychrotolerant aerobic or facultative anaerobic bacteria from the original collection were chosen as representatives of the diversity of the collection. The selected isolates were adapted to controlled laboratory growth conditions and both aqueous and organic extracts were produced following standard protocols already described for microorganisms [31]. In particular for the case of aqueous extracts, $20 \mathrm{~mL}$ of pure water were added to each 3 to $5 \mathrm{~g}$ of wet biomass. Cells were then broken using a high pressure homogenizer and the produced aqueous extracts were lyophilized and re-suspended in DMSO at a concentration of 
$25 \mathrm{mg} / \mathrm{mL}$. The UV absorbance measurement of the extracts was carried out using an ultraviolet-visible (UV-Vis) spectrophotometer (Evolution 300 Thermo Nicolet).

\subsection{Anti-UV Yeast-Based Assay Development and Screening}

Wild type BY4741 (MATa: his340; leu240; met1540; ura3 40 ) yeast was plated on a single layer on YPD solid media. Yeast cells were pre-grown for $16 \mathrm{~h}$ at $30{ }^{\circ} \mathrm{C}$ in YPD liquid media with agitation and then diluted to an $\mathrm{OD}_{600 \mathrm{~nm}}$ of 0.2 . When exponential phase was reached, $\mathrm{OD}_{600 \mathrm{~nm}}$ of 1 , cells were ten-fold diluted and spread on an YPD solid media plate at a density of $2000 \mathrm{cell} / \mathrm{s} / \mathrm{cm}^{2}$. For the UVC irradiation step a CAMAG UV lamp (255 nm) with an irradiance of $40 \mathrm{~mW} / \mathrm{cm}^{2}$ was used at a distance of $5 \mathrm{~cm}$ from the plate. For the UVB irradiation step a UVITEC LF-115.M lamp (312 nm) with an irradiance of $1.2 \mathrm{~mW} / \mathrm{cm}^{2}$ was used at a distance of $5 \mathrm{~cm}$ from the plate. For the UVA irradiation step a Hartmann UV-H lamp (365 nm) with an irradiance of $100 \mathrm{~mW} / \mathrm{cm}^{2}$ was used at a distance of $2 \mathrm{~cm}$ from the plate. Minimal lethal dose of radiation of each of the lamps, which corresponds to the minimum dose needed for complete inhibition of yeast cell growth, was determined by increments in the radiation dose achieved through increases in the exposure time. For the screening, 2 to $4 \mu \mathrm{L}$ of each aqueous extract at a concentration of $25 \mathrm{mg} / \mathrm{mL}$ in DMSO was added to the single-layer lawn of yeast cells and left to dry for a few minutes at room temperature. This was done in duplicate so that one set of plates was exposed to the minimal lethal dose of radiation, whereas the other set remained unexposed (control plates). Yeast plates were incubated at $30^{\circ} \mathrm{C}$ up to 4 days and cellular growth was analyzed by counting the number of yeast colonies able to survive to the minimal lethal dose of radiation.

\section{Conclusions}

In recent years, numerous compounds from marine natural products were isolated possessing interesting biological activities, mainly for the pharmaceutical industry. At the moment, at least three compounds are in Phase III trials, seven compounds are in Phase II, three compounds are in Phase I and other numerous marine natural products are currently investigated for different applications [32]. However, these numbers are still below the expectations. In contrast to sponges, corals and other marine invertebrates, marine microorganisms, in theory, do not possess reproducibility and scale up limitations, being able to supply sufficient amounts of the pure substances. In addition, the marine environment is so extreme that it may have given rise to the evolution of metabolic pathways with microorganisms producing new chemical entities [33]. In fact, from 1997 to 2008 around 660 new marine bacterial compounds were identified, being reasonable to expect that many more interesting bioactivities from these microorganisms are still to be found [34].

With the aim of developing a novel and industrially suited marine bacteria collection, 139 marine bacteria were selected from the 289 MAR hydrothermal vents isolates and 484 extracts were produced. This collection potential was previously tested with $65 \%$ showing bioactivity against CNS targets or some immune disorders targets, as well as interesting cosmetic potential or even enzymatic activities such as cellulase, chitinase, xylanase, pullulanase, lipase, pectinases and mannanase (data not shown). In this particular study, photoprotective capacity was demonstrated for $22 \%$ of the aqueous extracts tested, which is of extreme interest. Because crude aqueous extracts were tested for bioactivities, the chemical nature of the bioactive compounds is still unknown. In the case of strain $\mathrm{MGMS}_{2} 41 \mathrm{O}_{2}$, 
identified as Shewanella algae, one can speculate that melanin is probably the bioactive compound but in the case of strain $\mathrm{RBRS} 251 \mathrm{O}_{2}$, identified as Vibrio fluvialis, the photoprotective compound still needs to be identified. The association of secondary metabolites production with anti-UV photoprotection in microorganisms has already been established [16-18], but mainly when these microorganisms are isolated from exposed surfaces. Hence, its role in deep sea isolated microorganisms is very intriguing and might be explained by two, not excluded, hypotheses. One is that although MAR vents bacterial strains were isolated at depths where no UV light is detected, these were brought to the surface and adapted to grow in laboratory conditions where some UV light is now present. This may have triggered the production of photoprotective compounds that although not enough for a full protection may potentially intercept a fraction of the UV radiation conferring photoprotection in the yeast-based assay. The other possibility is that the metabolites responsible for the photoprotection are compounds that have a different role in their natural environment but that in favorable conditions may serve as photoprotectives. This would not be a novelty since several microbial sunscreens have alternative physiological roles [16-18] and should be exploited as novel chemical structures with interesting properties and modes of action may be identified. These novel compounds are of high interest for both pharmaceutical and cosmeceutical industries, for instance, where protective skin natural compounds are extremely needed. For the cosmeceutical industry, in which products are intended to enhance health and beauty of the skin, the bacterial extracts described in this work are of particular interest as they can be added directly in its crude state to already formulated products. In addition to these two industries, also astrobiological research is on high demand for new bioactives that protect against UV-C, such as bacterial melanin [17], which increases MAR vents bacteria extracts commercial value.

Interestingly, until just a few decades ago, it was widely accepted that microbes from extreme environments would require complex cultivation methods and would not likely produce metabolites other than those required for survival. It is clear from this work that, in fact, many of those microbes can be cultivated under standard laboratory conditions and are capable of novel and interesting natural product synthesis with market potential applications. As the global market for marine biotechnology products and processes is expected to reach $\$ 4.1$ billion by 2015 , with growth rates of around $12 \%$ in Europe [35], the exploitation of this collection for other industrially relevant bioactivities is indeed economically very appealing and is being pursued.

\section{Acknowledgments}

This work was supported by Project SEAHMA-Seafloor and Subseafloor Hydrothermal Modelling in Azores Sea (PDCTM/MAR/15281/99). Financial support from project D3B, QREN SI I\&DT Projectos Individuais, $\mathrm{n}^{\circ}$ 2008/1413, PORLisboa/QREN/UE and grant FCT/SFRH/BI/51091 . BIOALVO authors would like to say a special thanks to its team, and former trainee Margarida Silva, for their contribution to this work.

\section{Conflict of Interest}

The authors declare no conflict of interest. 


\section{References}

1. Molinski, T.F.; Dalisay, D.S.; Lievens, S.L.; Saludes, J.P. Drug development from marine natural products. Nat. Rev. Drug Discov. 2009, 8, 69-85.

2. Pettit, G.R.; Fujii, Y.; Hasler, J.A.; Schmidt, J.M. Isolation and characterization of palystatins A-D. J. Nat. Prod. 1982, 45, 272-276.

3. Sudek, S.; Lopanik, N.B.; Waggoner, L.E.; Hildebrand, M.; Anderson, C.; Liu, H.; Patel, A.; Sherman, D.H.; Haygood, M.G. Identification of the putative bryostatin polyketide synthase gene cluster from "Candidatus Endobugula sertula", the uncultivated microbial symbiont of the marine bryozoan Bugula neritina. J. Nat. Prod. 2007, 70, 67-74.

4. Arrieta, J.M.; Arnaud-Haond, S.; Duarte, C.M. What lies underneath: Conserving the oceans' genetic resources. Proc. Natl. Acad. Sci. USA 2010, 107, 18318-18324.

5. Takai, K.; Nakamura, K. Archaeal diversity and community development in deep-sea hydrothermal vents. Curr. Opin. Microbiol. 2011, 14, 282-291.

6. Rona, P.A.; Klinkhammer, G.; Nelsen, T.A.; Trefry, J.H.; Elderfield, H. Black smokers, massive sulfides and vent biota at the mid-atlantic ridge. Nature 1986, 321, 33-37.

7. Thornburg, C.C.; Zabriskie, T.M.; McPhail, K.L. Deep-sea hydrothermal vents: Potential hot spots for natural products discovery? J. Nat. Prod. 2010, 73, 489-499.

8. Amann, R.I.; Ludwig, W.; Schleifer, K.H. Phylogenetic identification and in situ detection of individual microbial cells without cultivation. Microbiol. Rev. 1995, 59, 143-169.

9. Jeanthon, C. Molecular ecology of hydrothermal vent microbial communities. Antonie Van Leeuwenhoek 2000, 77, 117-133.

10. Vandamme, P.; Pot, B.; Gillis, M.; de Vos, P.; Kersters, K.; Swings, J. Polyphasic taxonomy, a consensus approach to bacterial systematics. Microbiol. Rev. 1996, 60, 407-438.

11. Pot, B.; Peter, V.; Kersters, K. Analysis of Electrophoretic Whole-Organism Protein Fingerprints. In Chemical Methods in Prokaryotic Systematics; Goodfellow, M., O’Donnell, A.G., Eds.; Jon Wiley and Sons: London, UK, 1994; pp. 493-517.

12. Davidson, J.N. The effect of ultraviolet light on living yeast cells. Biochem. J. 1940, 34, 1537-1539.

13. Holick, M.F. Vitamin D: A millenium perspective. J. Cell. Biochem. 2003, 88, 296-307.

14. Torma, H.; Berne, B.; Vahlquist, A. UV irradiation and topical vitamin a modulate retinol esterification in hairless mouse epidermis. Acta Derm. Venereol. 1988, 68, 291-299.

15. Kollias, N.; Sayre, R.M.; Zeise, L.; Chedekel, M.R. Photoprotection by melanin. J. Photochem. Photobiol. B Biol. 1991, 9, 135-160.

16. Plonka, P.M.; Grabacka, M. Melanin synthesis in microorganisms_-biotechnological and medical aspects. Acta Biochim. Pol. 2006, 53, 429-443.

17. Gao, Q.; Garcia-Pichel, F. Microbial ultraviolet sunscreens. Nat. Rev. Microbiol. 2011, 9, 791-802.

18. Pallela, R.; Na-Young, Y.; Kim, S.K. Anti-photoaging and photoprotective compounds derived from marine organisms. Mar. Drugs 2010, 8, 1189-1202.

19. Gadanho, M.; Sampaio, J.P. Occurrence and diversity of yeasts in the mid-atlantic ridge hydrothermal fields near the azores archipelago. Microb. Ecol. 2005, 50, 408-417. 
20. Gevers, D.; Cohan, F.M.; Lawrence, J.G.; Spratt, B.G.; Coenye, T.; Feil, E.J.; Stackebrandt, E.; van de Peer, Y.; Vandamme, P.; Thompson, F.L.; et al. Opinion: Re-evaluating prokaryotic species. Nat. Rev. Microbiol. 2005, 3, 733-739.

21. Turick, C.E.; Tisa, L.S.; Caccavo, F., Jr. Melanin production and use as a soluble electron shuttle for Fe(III) oxide reduction and as a terminal electron acceptor by Shewanella algae BrY. Appl. Environ. Microbiol. 2002, 68, 2436-2444.

22. Valeru, S.P.; Rompikuntal, P.K.; Ishikawa, T.; Vaitkevicius, K.; Sjoling, A.; Dolganov, N.; Zhu, J.; Schoolnik, G.; Wai, S.N. Role of melanin pigment in expression of Vibrio cholerae virulence factors. Infect. Immun. 2009, 77, 935-942.

23. Tudor, L.; Togoe, I.; Enache, L.; Georgescu, B. UV influence over Vibrio bacterial species. Roum. Biotechnol. Lett. 2002, 3, 767-772.

24. Pitcher, D.G.; Saunders, N.A.; Owen, R.J. Rapid extraction of bacterial genomic DNA with guanidium thiocyanate. Lett. Appl. Microbiol. 1989, 8, 151-156.

25. Chambel, L.; Sol, M.; Fernandes, I.; Barbosa, M.; Zilhao, I.; Barata, B.; Jordan, S.; Perni, S.; Shama, G.; Adriao, A.; et al. Occurrence and persistence of Listeria spp. In the environment of ewe and cow's milk cheese dairies in portugal unveiled by an integrated analysis of identification, typing and spatial-temporal mapping along production cycle. Int. J. Food Microbiol. 2007, 116, $52-63$.

26. Ludwig, J.A.; Reynolds, J.F. Diversity Indices. In Statistical Ecology: A Primer on Methods and Computing; John Wiley \& Sons: New York, NY, USA, 1988; Volume 8, pp. 85-101.

27. Kremer, A.; Petit, R.; Pons, O. Measures of Polymorphism within and among Populations. In Molecular Tools for Screening Biodiversity; Karp, A., Isaac, P., Ingram, D., Eds.; Chapman \& Hall: London, UK, 1998.

28. Thompson, J.D.; Gibson, T.J.; Plewniak, F.; Jeanmougin, F.; Higgins, D.G. The CLUSTAL_X windows interface: Flexible strategies for multiple sequence alignment aided by quality analysis tools. Nucleic Acids Res. 1997, 25, 4876-4882.

29. Huelsenbeck, J.P.; Ronquist, F. Mrbayes: Bayesian inference of phylogenetic trees. Bioinformatics 2001, 17, 754-755.

30. Larget, B.; Simon, D.L. Markov chain monte carlo algorithms for the bayesian analysis of phylogenetic trees. Mol. Biol. Evol. 1999, 16, 750-759.

31. Sarker, S.D.; Latif, Z.; Gray, A.I. Natural Products Isolation, 2nd ed.; Humana Press: New York, NY, USA, 2006.

32. Mayer, A.M.; Rodriguez, A.D.; Berlinck, R.G.; Fusetani, N. Marine pharmacology in 2007-8: Marine compounds with antibacterial, anticoagulant, antifungal, anti-inflammatory, antimalarial, antiprotozoal, antituberculosis, and antiviral activities; Affecting the immune and nervous system, and other miscellaneous mechanisms of action. Comp. Biochem. Physiol. C Toxicol. Pharmacol. 2011, 153, 191-222.

33. Blunt, J.W.; Copp, B.R.; Munro, M.H.; Northcote, P.T.; Prinsep, M.R. Marine natural products. Nat. Prod. Rep. 2011, 28, 196-268.

34. Imhoff, J.F.; Labes, A.; Wiese, J. Bio-mining the microbial treasures of the ocean: New natural products. Biotechnol. Adv. 2011, 29, 468-482. 
35. Glass Market Research Reports. Available online: http://www.giiresearch.com/topics/ MR08_en.shtml (accessed on 21 February 2012).

(C) 2013 by the authors; licensee MDPI, Basel, Switzerland. This article is an open access article distributed under the terms and conditions of the Creative Commons Attribution license (http://creativecommons.org/licenses/by/3.0/). 